\title{
28
}

\section{DECENTRALISED DECISION MAKING IN NON-HIERARCHICAL NETWORKS}

\author{
Egon Müller ${ }^{1}$; Sebastian Horbach ${ }^{1}$; Jörg Ackermann ${ }^{1}$ \\ Institute of Industrial Science and Factory Systems, \\ Chemnitz University of Technology, GERMANY \\ egon.mueller@mb.tu-chemnitz.de \\ sebastian.horbach@mb.tu-chemnitz.de \\ joerg.ackermann@mb.tu-chemnitz.de
}

\begin{abstract}
Autonomous, elementary units of production, co-operating in temporary networks, are considered as the organisational form of enterprises in the 21st century. A scientific approach is provided by networks based on customeroriented, directly linked, smallest autonomous business units called Competence Cells.

Simultaneously this concept points out perspectives for present-day small and medium-sized enterprises (SME) to face ever-changing economic conditions. One objective is to make SMEs fit for global supply chain integration as well as collaborative management of complex manufacturing and logistics tasks in several production networks at the same time.

For a decentralised decision making based on the non-hierarchical business model special business logics, algorithms and methods for supply chain integration and management need to be provided and implemented in services and applications.

A first core logic is focused on the matching of partners for composition and operation of temporary production networks. Contrary to existing web portals the basic idea is to make the linking interactive and more flexible by using of different description constructs regarding to satisfy the customer, but also network goals. A second core logic addresses the cascading selection of the partners for a customer order driven supply chain. Firstly the "nodes" (manufacturing, assembly, testing) have to be chosen, secondly the "relations" (logistics). A third core logic deals with these "relations". The idea is to establish an automated determination of the logistic processes and candidates.
\end{abstract}

\section{INTRODUCTION}

The economical impact of small and medium-sized enterprises (SME) is undisputed (European Commission, 2007; Verheugen, 2008). In Europe-27 there are 23 million SMEs (99.7\% of all European enterprises), which provide work for about 75 million people (up to $80 \%$ of the employees in some industrial sectors). European manufacturing industry is embracing the following characteristic transitions and changes (Gregory, 2007): 1. Local to global, 2. Factories to networks, 3. Commoditise to innovate, 4 . Volume to flexibility, 5. Hierarchies to teams, 6. Craft to knowledge-based.

Most of today's SME networks are working in a regional environment (Havnes, 2004). Supra-regional global engagements are observed less, but in the future SMEs will have to operate more globally in an agile manner. The management of the 
participation in several networks at the same time is a complex problem. SMEs struggle to handle this due to a lack of methodological skills and human resources. In result the decision making is chaotic. SME are not able to build and operate complete supply chains e.g. to find the right partners and to keep the costs low.

There is a need to make SMEs fit for global supply chain integration as well as collaborative management of complex manufacturing and logistics tasks in several production networks at the same time. Therefore, a scientific approach and the associated systematic robust implementation methodology is essential and much needed for supporting European manufacturing industry, SMEs in particular, to competitively engage in the dynamic global manufacturing and supply chains.

An approach is requested to point out perspectives for present-day SMEs to face ever-changing economic conditions. Such a scientific approach is provided by networks based on customer-oriented, directly linked, smallest autonomous business units called Competence Cells (Mueller, 2006; Mueller, 2007).

This approach is justified by studies, that autonomous, elementary business units co-operating in temporary networks are considered as one of the most sustainable organisational forms of enterprises in the 21st century (see MIT- and OECD-studies (Laubacher et al., 1997; OECD, 2001)).

\section{NON-HIERARCHICAL NETWORKS}

The scientific approach and its systematic robust implementation has been exclusively researched at Chemnitz University of Technology in the research projects "Non-hierarchical Regional Production Networks" (Collaborative Research Centre 457, duration 2000-2006, see (Mueller, 2007)) and "Competence Cell based Production Networks" (Project Cluster 196, duration 2007-2009, see (Mueller, 2006)).

The research on competence cells-based non-hierarchical production networks is unique. Usually, strategic, hierarchical corporate networks are the object of research. In the European scientific landscape, there has been an increased concentration on "Virtual Organisations" (starting with Mowshowitz, 1994) and "Collaborative Business Networks" (e.g. Camarinha-Matos et al., 2006) for several years now. In most cases, analogue basic assumptions are made compared to the vision of nonhierarchical networks, which confirms the approach. All of the research projects share the ambition to find new organisational forms. But the characteristics of the analysed competence cell-based networking approach are not considered explicitly.

\subsection{Vision}

The vision of the competence cell-based networking approach (Figure 1) is the following:

Elementary business units - called Competence Cells - are co-operating in Nonhierarchical Regional Production Networks in a customer-oriented manner and thus are capable of facing global competition. 


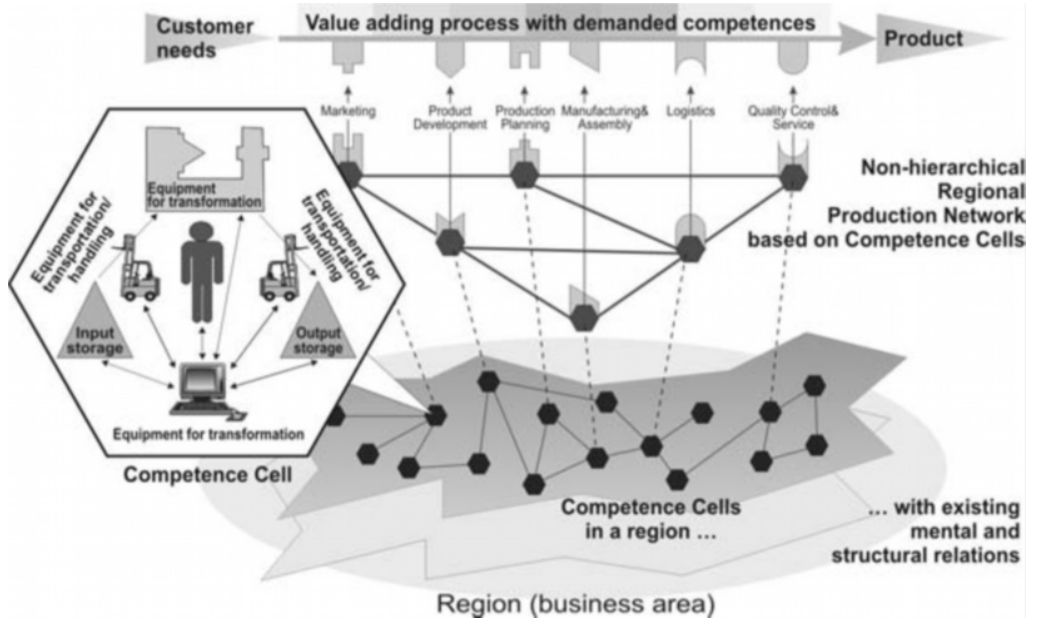

Figure 1 - Conception of Non-hierarchical Regional Production Networks (Mueller, 2007)

\subsection{Models and Methods for non-hierarchical environments}

In order to substantiate the vision of competence cell-based networking a model for the Competence Cell (Figure 3) and a procedure model for the networking (Figure 2 ) as well as an operationalised concept of organisation (Figure 2) were developed.

\section{Model of the Competence Cell}

A Competence Cell (see Figures 1 and Figure 3 left) is considered as the smallest autonomous indivisible business unit of value adding, able to exist independently.

The model of the Competence Cell consists of:

- the human with his competences, arranged according to professional, methodical, social and personnel competences (Erpenbeck, 1998)

- available resources as well as

- $\quad$ the fulfilled task or executed function.

With this function a business entity can be transformed and a certain performance can be achieved. The aspects of dimension and structure were supplemented to obtain a complete technical description.

\section{Procedure Model for networking}

The procedure model (Figure 2, left) comprises three levels and seven phases.

From loose infrastructural and mental relations present in a regional network (Level I) there initially emerges an institutionalised Competence Network, based on Competence Cells (Level II, phase Competence Network Composition). Institutionalisation takes place via the coordination of behaviour (e.g. agreements on offer generation, agreements on cost allocation) and via the pooling of capacity (e.g. common servers and data bases). These facilitate an efficient acting towards the customer and avoid internal discrepancies. Institutionalisation thereby creates the basis on which autonomous Competence Cells join to find to a collective creation of 
value. In order to hold fixed expenses down, the institutionalisation is to be limited to the necessary amount.

The actual creation of value takes place in a Production Network (Level III, phase Production Network composition), i.e. a temporary linking of selected Competence Cells, initiated by a customer's request. In order to select and cross-link Competence Cells and to operate the network, co-ordinated ways of behaviour and pre-installed structures are available in the Competence Network.

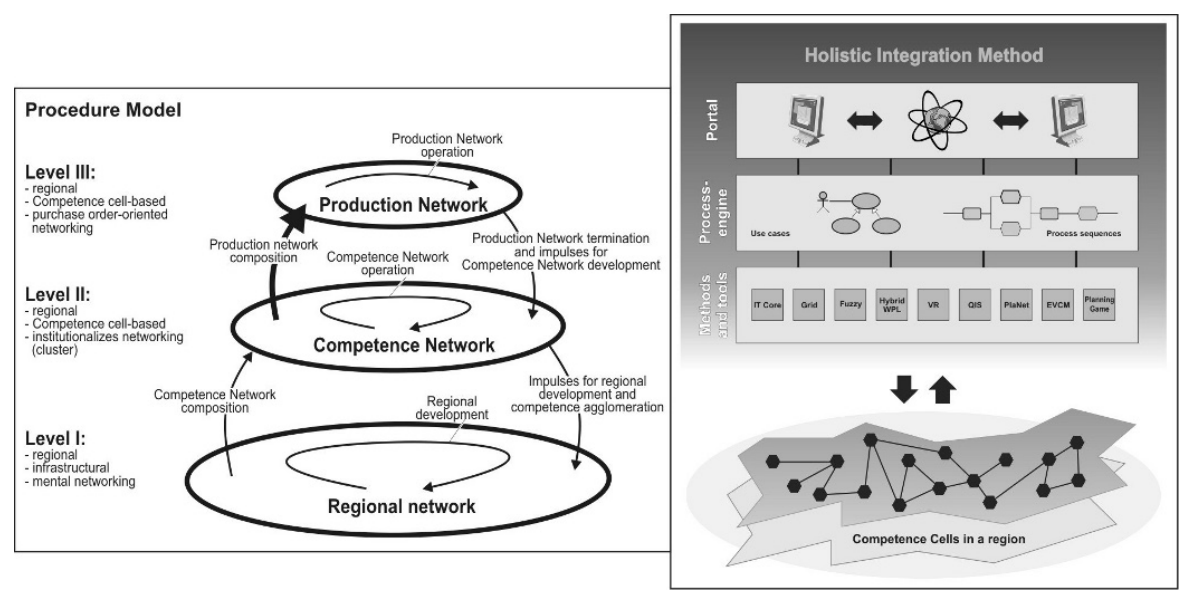

Figure 2 - Procedure model of competence cell-based networking and holistic integration method (Mueller, 2007)

\section{Holistic Integration Method}

For running the innovative type of cooperation "Non-hierarchical Regional Production Networks" an operationalised concept of organisation is needed. Such a concept was developed with the "holistic integration method" (HIM). HIM marks a comprehensive instruction as a kind of organisational manual for the Competence Cells. It is based on the levels and phases of the Procedure Model. The general architecture of HIM consists of the levels "Portal", "Process Engine" and "Methods\&Tools".

The Competence Cells as users access the functions of HIM through a webbased portal. The portal is linked to the Process Engine. On the highest level of the Process Engine typical cooperative use cases respectively procedures inside the levels and phases of the Procedure Model are defined. In the lowest level the different methods are described in an application-driven form and, if applicable, linked to supporting software tools.

\section{DECENTRALISED DECISION MAKING}

For a decentralised decision making based on the non-hierarchical business model special business logics, algorithms and methods for supply chain integration and management need to be provided and implemented into services and applications. Three essential core logics are explained in detail. 


\subsection{Matching}

A first core logic is focused on the matching of partners for composition and operation of temporary production networks. Contrary to existing web portals (see eMarketDirectory, 2008) the basic idea is to make the linking interactive and more flexible by using different description constructs (performance, function, competence, resource) in order to satisfy the customer, but also network goals.

The matching of the Competence Cells to a value adding process can be realised in a cascading manner using different description categories depending on the objectives of the customer, the network and the different Competence Cells (Figure 3).

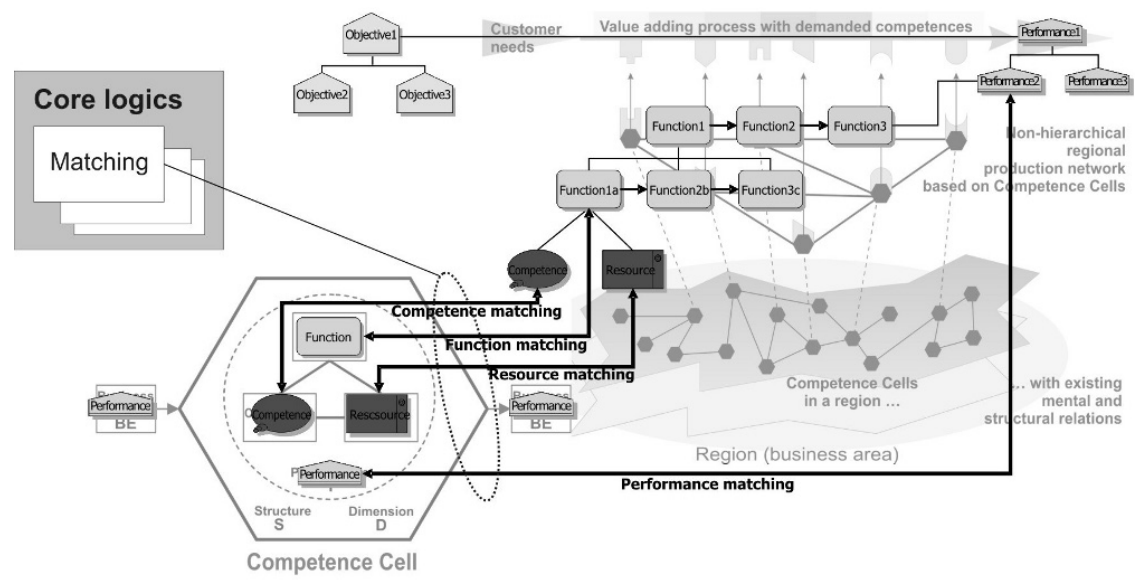

Figure 3 - Matching of Competence Cells to value added processes using different description categories

The matching can be performed using the requested and offered performances, which can also be divided into sub-performances. In case of an entire or a partial failure, the performances can be transformed into functions necessary for their realisation. Then, a matching can be performed using the requested and offered functions, which can also be divided into sub-functions. In case of an entire or a partial failure, the carriers of the functions in terms of competences and resources can be assigned to the functions. Then, a matching can be performed using the requested and offered competences or resources.

\subsection{Selection}

A second core logic addresses the cascading selection and assigning of the partners to a customer order driven supply chain in two steps. First, the non-logistic candidates (manufacturing, assembly, testing) as the "nodes" are assigned. Then, the logistic candidates (storage, transport) as the "relations" are assigned.

One basic idea is the automation of the configuration procedures. Only if the automated configuration of the production networks fails a complementing planning procedure is deployed (Mueller, 2007). Existing models, concepts and methods for networks are only partially suitable for this (e.g. Herzog, 2008; Kuhn, 2008). 
The concepts Extended Value Chain Management (EVCM) and IT core were developed for the automated configuration and operation of Non-hierarchical Regional Production Networks (see Goerlitz et al., 2002). They support the selforganisation (see Herzog, 2008) which is inherent in such networks.

The IT core serves the administration of the data on Competence Cells and variants for production networks. EVCM comprises the necessary business logic with algorithms for the recursive mechanism of creating queries/offers of Competence Cells (Roll-out/Roll-in). It organises the selection of Competence Cells, the administration of the offer data and the determination of the optimal production network configuration. During the operation of the production network EVCM realises the coordination and controlling of the project and order processing.

\subsection{Relations}

A third core logic deals with the "relations". Several methods exist for the assigning of the logistic processes and candidates. One special idea is to establish an automated determination.

For a complete automated generating of value chains an automated determination of logistic processes and Competence Cells (candidates) is necessary. A number of possible procedures were reviewed. Two possible variants are shortly described. Both variants start with the determination of the non-logistic processes and Competence Cells. Starting with the customer and continued for the whole value adding process in a backward scheduling the following steps are completed in interplay between IT core and EVCM: 1. Determination of destination node, 2. Determination of edge time, 3. Determination of source node.

In result of the determination of potential nodes a process variant plan (Subprocesses for manufacturing, assembly, quality assurance) and a respective candidate graph are available. These provide the necessary logistical input (e.g. load unit, time window, source/destination location) for the determination of the edges (determination of logistic processes and Competence Cells). From those offers are requested simultaneously. Potential - usually transport - Competence Cells for covering the edges are found by the IT core and enquired by EVCM.

In a first variant transport Competence Cells place an offer for the complete edge. The offer is stored in the offer graph. If they are not able to cover an edge completely themselves they will generate a sub-query for additional transport and storage Competence Cells.

A second variant allows transport Competence Cells to place only partial offers for the edges. If due to a large time window storage is necessary the transport Competence Cells only place offers for the two respective transports of the edge. In the offers additional conditions for storage (time window, distances to storage places) are stated. Then storage Competence Cells can be enquired.

If all value adding processes and candidate Competence Cells are assigned an optimal alternative for the production network can be found according to the preferred objective function of the customer. The resulting production network will start operation then. 


\section{IMPLEMENTATION}

A first prototypical implementation of the matching logic (Figure 3) for demonstration has been realised as a web-based portal (Figure 4).

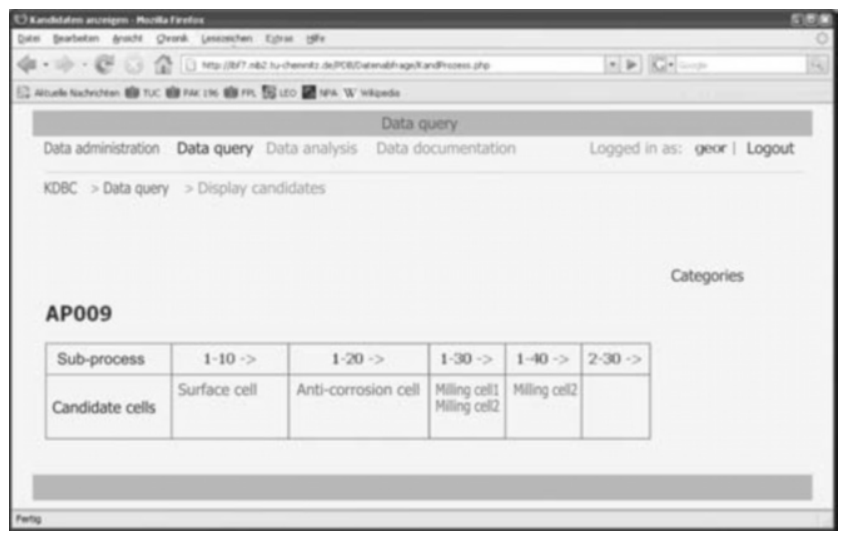

Figure 4 - Web-based portal for matching with an example

Candidates can be searched by the description constructs performances, processes, resources, and competences. Performances are decomposed in subperformances while processes are decomposed in sub-processes i.e. functions if they are elementary. On the one hand performances, processes, and resources can be selected from existing data. On the other hand complex performances and processes can be composed from existing elementary performances and processes.

If a resource or a competence was selected candidates which own the resource or competence are displayed. In case of the selection of performances or processes candidates are displayed for each elementary sub-performance or sub-process. Usually there is more than one candidate for an item. It is however also possible that no candidate can be found, thus suggesting a deficit in the profile of the network.

Figure 4 illustrates the finding of candidates for a whole work process (AP009). The user picked an already existing process and is provided with a list of Competence Cells which can realise the different sub-processes. There is no candidate for the last sub-process. This means that the Competence Network is lacking competence in a certain field. That way, deficits can be easily identified.

\section{SUMMARY}

The models and methods of the competence-cell based networking approach especially the core logics - are expected to contribute to the creation of agile globally operating non-hierarchical supply chains in a systematic way. Thus they will manage the density of information along the supply chain, overcome the complexity of working in several supply chains, ensure flexibility and transparency, and reduce the costs (expenses). The methods and implementing tools will help SME to do the step from currently regional to supra-regional networking. 
The methods/services and resulting applications are expected to address many stakeholders:

- Customers can create process chains for both concrete and fictive orders in order to "see" potential partners.

- Enterprises can create process chains for customer requests or product ideas. They have the chance to exploit new markets and to position themselves at these markets.

- Institutions and incorporations can systematically perform regional development because potentials as well as deficits can be recognised.

\section{ACKNOWLEDGEMENTS}

The work which is presented in this paper has been supported by the German Research Foundation (Deutsche Forschungsgemeinschaft - DFG).

\section{REFERENCES}

1. Camarinha-Matos LM, Afsarmanesh H, Ollus M (eds.). Networks-Centric Collaboration and Supporting Frameworks. IFIP TC5 WG 5.5 Seventh Working Conference on Virtual Enterprises. Helsinki, Finland, 25-27 September 2006, New York: Springer, 2006.

2. eMarketServices. Do more business with Electronic marketplaces: eMarketDirectory, 2008, http://www.emarketservices.com/start/eMarket-Directory/index.html (accessed 2008-03-04).

3. Erpenbeck J. Kompetenzentwicklung als Forschungsaufgabe. QUEM Bulletin 2/3, 1998.

4. European Commission. Survey of the Observatory of European SMEs. Observatory of European SMEs, Flash EB Series \#196. Luxembourg: Office for Official Publications of the European Communities, 2007.

5. Goerlitz O, Neubert R, Teich T, Benn W. "Extended Value Chain Management on electronic marketplaces". In International Journal of E-Business Strategy Management. Vol. III No. 3/2002, London: Winthrop Publications Limited, 2002.

6. Gregory M. Understanding and Interpreting the Future. Report, Cambridge: University, Institute for Manufacturing, 2007.

7. Havnes PA. SMEs and Cooperation. Observatory of European SMEs. Report 2003/5. Luxembourg: Office for Official Publications of the European Communities, 2004.

8. Herzog O (ed.). Collaborative Research Centre (CRC) 637: Autonomous Cooperating Logistics Processes. A Paradigm Shift and its Limitations. Bremen: University, 2008, http://www.sfb637.uni-bremen.de/?\&L=2 (accessed 2008-02-28).

9. Kuhn A (ed.): Collaborative Research Center (CRC) 559: Modelling of Large Logistics Networks. Dortmund: University of Technology, 2008. http://www.sfb559.uni-dortmund.de/intro_en.php? sprache=en (accessed 2008-02-28).

10. Laubacher RJ, Malone TW, MIT Scenario Working Group. Two Scenarios for 21st Century Organizations - Shifting Networks of Small Firms or All-Encompassing 'Virtual Countries'? MIT Initiative on Inventing the Organizations of the 21st Century, Working Paper 21C WP \#001, 1997.

11. Mowshowitz A. Virtual Organization: A Vision of Management in the Information Age. The information society 1994; 10(4): 267-288.

12. Mueller E (ed.). Collaborative Research Centre (CRC) 457: Non-hierarchical Regional Production Networks. Final Report, Chemnitz: University of Technology. 2007.

13. Mueller E (ed.). Project Cluster (PAK) 196: Competence Cell based Production Networks. Proposal, Chemnitz: University of Technology, 2006, http://www.tu-chemnitz.de/PAK196/en/ (accessed 2008-03-04).

14. OECD. World Congress on Local Clusters: Local Networks of Enterprises in the World Economy. OECD Issues paper, Paris, 23-24 January 2001.

15. Verheugen G. Small business act for Europe. Speech of the Vice-President of the European Commission responsible for Enterprise and Industry, Commission hearing, Brussels, 6 February 2008. 